Revista de la red interuniversitaria de estudios sobre las literaturas rioplatenses contemporáneas en Francia

$10 \mid 2014$

El XIX en el XX

\title{
Cuando escribimos
}

\section{Sergio Delgado}

URL: http://journals.openedition.org/lirico/1693

DOI: $10.4000 /$ lirico. 1693

ISSN: 2262-8339

Editor

Réseau interuniversitaire d'étude des littératures contemporaines du Río de la Plata

\section{Referencia electrónica}

Sergio Delgado, « Cuando escribimos », Cuadernos LIRICO [En línea], 10 | 2014, Puesto en línea el 15 marzo 2014, consultado el 19 abril 2019. URL : http://journals.openedition.org/lirico/1693 ; DOI : 10.4000/lirico.1693

Este documento fue generado automáticamente el 19 abril 2019.

\section{(c) $(1) \Theta \Theta$}

Cuadernos LIRICO está distribuido bajo una Licencia Creative Commons Atribución-NoComercialSinDerivar 4.0 Internacional. 


\title{
Cuando escribimos
}

\section{Sergio Delgado}

\author{
"El espíritu de un intelectual debe hacer siempre, \\ en sí mismo, un lugar al Otro extranjero. Y esta \\ acción creadora de abrirse al Otro, que de otro \\ modo permanece extranjero, es la dimensión más \\ importante de la tarea de un intelectual."
}

EDWARD SAID

1 Una respuesta al tema planteado en esta mesa, los "Usos estéticos y políticos del pasado : el XIX en la literatura argentina del presente", puede intentarse a partir de la propia experiencia de escritura. Cada uno de nosotros confronta a diario este desafío, tanto en la modalidad del ensayo, la narración o el poema (si acaso estas prácticas pueden, en este dominio, separarse claramente) y también, en algunos casos, en la edición. En lo que me concierne, me siento particularmente implicado como narrador puesto que acabo de terminar (o más bien : estoy comenzando a terminar) un tríptico de relatos que llamo $\mathrm{El}$ paraíso que a lo largo de tres años de trabajo me llevó a preguntarme recurrentemente respecto al problema de la representación del pasado, respecto a las maneras como se hacen presentes o perviven en el presente ciertos hechos del pasado y, en particular, respecto a aquellas formas o mitos o relatos que, viniendo del pasado, digamos del siglo XIX (es decir : aquellos años que concebimos, oscuramente, como los de la fundación de nuestra literatura), siguen actuando directa o indirectamente en nosotros, incluso cuando intentamos hablar de la más inmediata realidad. No pienso, si es necesario aclararlo, en esos usos didácticos o publicitarios de la historia con los que algunos escritores pretenden llevar a o traer al lector, de manera forzosa y en consecuencia irresponsable, a un territorio de reconocimiento mutuo, sino en ese pasado que, como exclamaba un personaje de Joyce, "es una pesadilla de la que estoy tratando de despertar"1.

Se me dirá que no debería colocar mi experiencia en un rango ejemplar. Es cierto y por varios motivos. Vivo en Francia, alejado de Argentina, desde hace casi quince años y cada vez me siento menos involucrado por las producciones literarias y las discusiones intelectuales que allá suelen encender los espíritus. Para ser honesto debo decir que cuando vivía en Argentina, en Santa Fe, esa capital de provincia situada junto a una gran 
laguna, en una región que podríamos llamar del Paraná Medio, antes de venir a Francia, hacia fines de los años 90, esta distancia ya estaba de alguna manera presente. Es cierto, sí, que no puedo ni debo generalizar desde mi situación particular pero en el mismo momento en que acepto la observación algo en mí se rebela : me resultaría muy difícil, para invertir el problema, aceptar una reflexión teórica respecto a la literatura argentina que no considerara, aunque más no sea como la excepción a alguna regla, un caso como el mío. Me vienen a la mente ahora estos versos de Vallejo : "Mi madre me ajusta el cuello del abrigo, no porque empieza a nevar, sino para que empiece a nevar."

Hay al escribir en primera persona un doble movimiento, hacia uno mismo y hacia el otro, donde exploramos los límites, respectivamente, de una procedencia y una pertenencia. Cuando utilizo, cuando utilizamos la primera persona, en sus múltiples oscilaciones de lo singular a lo plural (basta que seamos dos para decir nosotros), lo subjetivo busca siempre, indiscerniblemente, al mismo tiempo decirse y disimularse. La gramática más básica nos advierte del engaño que reside en la pluralidad de todo nosotros, que va del decir "yo y otros conmigo" hasta las complejas operaciones de las formas llamadas mayestáticas o de modestia, en la búsqueda, la mayoría de las veces de manera improbable, de un efecto de autoridad, de objetivad, de impersonalidad e incluso de una complicidad con el lector. Cuando pierdo el yo adviene una dimensión colectiva que me desborda, que nos desborda. Ese otro que nace en nuestra propia escritura llega hasta el lector, ustedes, que me están escuchando en este momento, pero nadie puede comprobarlo. Ni yo mismo, ni nosotros, aquí, ahora.

Cuando escribo, cuando escribimos, lo hacemos en presente. Por más esquemas, planes, investigaciones que hayamos desarrollado de manera previa a la escritura de la narración, el ensayo o el poema, siempre escribimos ahora. $Y$ en el momento en que nos preguntamos, sobre la naturaleza de ese presente, la escritura vacila. Es muy difícil, si no imposible, determinar -como nos ocurre con el yo del yo o el nosotros del nosotros- que aquello que traemos del pasado es acaso de naturaleza distinta de aquello que ya estaba en el presente, haciéndolo posible. Hechos, temas o formas del pasado, tomados de nuestra literatura o de literaturas extranjeras, cuando son traídos al presente de la escritura, si logran sacarse de encima las telarañas o el polvo del depósito, los modismos o acentos de su carácter inmigrante, resisten sólo cuando ese presente los vuelve posibles. Pero hay momentos en que esto no ocurre. Es extenso ese terreno, más bien fronterizo, donde tiene lugar la apropiación. Una dimensión tan poblada de cadáveres exquisitos y de fantasmas ilustres que a veces resulta inhabitable pero a la que no podemos renunciar puesto que es la única casa donde se nos permite ser.

5 "Zona peligrosa" de César Aira, artículo publicado en abril de 1987 en la revista El porteño, acaba de ser resucitado por algunos blogs, como es el caso de los siempre estimulantes Apóstrofe y Golosina canibal, con la perplejidad de quien sorprende, en cartas encontradas en algún un recóndito cajón, pecados juveniles de nuestros abuelos. En ese artículo Aira analiza la obra de Saer, hasta Glosa (novela que en ese momento era la última publicada), con inteligencia pero deslizando, aquí y allá, una serie incongruente de pequeñas maldades que hoy deslumbra a los bloguistas y que en su momento, cuando la obra de Saer comenzaba precisamente a ser reconocida, produjo un cierto revuelo (sobre todo en el ánimo de Saer). Encontramos aquí un magnífico ejemplo de asteísmo, esa figura tan 
rioplatense que consiste en un discurso fuertemente despreciativo que puede o debería leerse, de manera más bien indirecta, como un elogio. El elogio encubierto como figura retórica tiene una tradición milenaria pero lejos de constituirse en pieza de museo, carne de diccionarios, es visitada frecuentemente en la vida cotidiana. Dos amigos del alma se encuentran y uno le dice al otro : "Qué hacés, hijo de puta". Es evidente que el primero está convencido de que su amigo es exactamente lo contrario de un perfecto hijo de puta, pero por una suerte de pudor viril no se permite decírselo y el otro, por mecanismos que son totalmente ajenos a las palabras, comprende lo que debe comprenderse y ambos se sonríen y se abrazan. Sería interesante hacer un estudio del asteísmo argentino, pero esto escapa, indudablemente a las posibilidades de esta ponencia. En su artículo Aira habla de Saer como si estuviera ante el mal alumno de un taller literario que se esfuerza inútilmente por escribir bien, lográndolo por momentos, pero sin posibilidad alguna de alcanzar el arte verdadero. Es decir : habla de Saer como si hablara de Vlady Kociancich o de Claudia Piñeiro. En otro plano, puede interpretarse que, para Aira, Saer es exactamente lo contrario de lo que su artículo da a entender, no sólo porque acá y allá lo califica, con estas u otras palabras, de "artista verdadero", sino, de una manera más profunda y si se quiere más sutil, por la calidad de la lectura que hace de su obra. En particular de las que en ese momento eran sus dos últimas novelas : El entenado (1983) y Glosa (1986). Aira lee a Saer como se lee a todo escritor verdadero, es decir comprendiendo inmediatamente, por una suerte de intuición secreta, que algo oculto en su obra merece ser desentrañado -independientemente del sistema construido para leerla- y que la vida del lector, a partir de este encuentro, se ha visto transformada para siempre. Aira no es el mismo después de haber leído Saer.

6 Me interesa detenerme en la lectura que Aira hace de El entenado, donde cree percibir dos planes o proyectos : "uno primitivo sobre el qué realizó la invención novelesca (la tribu de caníbales, la arqueología de su Colastiné 'reino encantado'), y otro al que en definitiva se subordinó el primero, y que podría resumirse más o menos así : un actor que ha hecho fortuna representando en teatros y ferias europeos el papel del cautivo entre salvajes, a la vejez escribe su vida, y por la vía, o el nudo, de la teatralidad, crea el género literario de la Antropología". De esta manera, concluye Aira, el entenado, ese grumete español, huérfano, criado en los puertos, que acompañó una expedición al Río de la Plata y que permaneció diez años cautivo entre los indios antes de poder volver a su patria, resulta ser una suerte de "hijo de sus obras". Y no tanto por el hecho de escribir su vida, como por el de representarla. La calidad de la lectura de Aira, que es el terreno donde se dirime el elogio, se prolonga además en su propia obra. En Un episodio en la vida del pintor viajero (2000), donde Aira cuenta la historia del pintor alemán, Johan Moritz Rugendas (según Sarmiento, que lo conoció en Brasil, de paso en su Viaje hacia Europa, un especialista en la representación del "rapto de cristianas"), los indios interpretan, también ante los ojos de un europeo, los pasos de un malón, como una suerte de espectáculo circense o desfile. Atacan un tambo a los alaridos, lanzas en alto, mientras los defensores y las vacas, entre indiferentes, desafiantes o burlones, disparan tiros de salva al aire o se echan al suelo a descansar. Los "salvajes" interpretan en particular el robo de "cautivas", rasgo que define todo malón, pero las "cautivas" que llevan "cruzadas sobre el cuello del animal" son en realidad indios disfrazados de mujeres o en su defecto una ternera blanca o un "descomunal salmón rosado". Es difícil saber a ciencia cierta si la representación existe en realidad o surge de la mirada alucinada del pintor, a quien, literalmente, poco tiempo antes, lo partió un rayo y en la espantada del caballo su rostro sufrió una deformación 
monstruosa. En definitiva, entre sus nervios atravesados incesantemente por corrientes eléctricas y sus venas saturadas de morfina, el pintor europeo sólo ve lo que puede llegar a ver.

7 ¿Qué es lo que nos hace volver sobre ciertos temas o formas? ¿De qué manera un tema como la "cautividad" se nos presenta hoy, en sus variaciones más insólitas, y nos permite seguir escribiendo en argentino? Aira lector de Saer, lector de Borges, lector de Sarmiento, lector de Echeverría, nos brinda su testimonio.

Sin embargo cuando escribo, cuando escribimos, la literatura argentina no existe. No más, en todo caso, que la literatura francesa, belga, irlandesa, china, española, italiana, peruana, alemana, nicaragüense, rusa o japonesa, entre otras que leemos frecuentemente. Es inevitable que sea así. Lo raro sería que fuera distinto. En ese sentido ser argentino, como diría Borges, es más bien una fatalidad y todos nuestros temas y las formas que empleamos para abordarlos concurren a ese horizonte que traza la línea de lo escrito. Es casi imposible no ser -quizás menos en el momento de empezar a escribir que en el de dejar de escribir-, al fin de cuentas, argentinos.

Esto no tiene nada que ver, no necesariamente, con la condición del exilio. Al menos no en términos que aquí pudieran discutirse. Cabe en todo caso la siguiente pregunta retórica : si acaso la Argentina como nación desapareciera, si por ejemplo un cataclismo atmosférico borrara el territorio del mapa; si de pronto (y de una vez por toda), Chile, Bolivia, Paraguay, Brasil y Uruguay se pusieran de acuerdo y decidieran librar al continente americano de argentinos, invadiéndonos y proclamando por ejemplo la República del Cono Sur ; si esto ocurriera, yo, nosotros, ¿seguiría, seguiríamos siendo argentino, argentinos? Probablemente sí y quizás más que nunca, en la misma medida que Mahmoud Darwich o Edward Said insistieron toda su vida en definirse como palestinos. Se trata de una condición que abreva en ciertos recuerdos personales, en cierta luz de la infancia, que se nutre sobre todo en esa particular nostalgia que procura la distancia o la ausencia : una sensación, al mismo tiempo individual y colectiva, de que somos un ser incompleto, que nos falta algo nos ha sido quitado y se nos debe desde siempre.

10 Me aproximo al tema de la mesa problematizando el presente de la escritura. Cuando escribimos habitamos en el presente pero con incomodidad. En varias oportunidades cité las palabras con que Sarmiento comienza su Campaña en el Ejército Grande :

"Si alguno de los millares de argentinos que han recibido heridas graves en nuestras eternas luchas civiles, leyere estas páginas, recordará aquella extraña sensación que se experimenta al recobrar el uso de la razón, y abriendo los ojos no poderse dar cuenta de sí mismo y preguntarse interiormente ¿quién soy y qué lugares son estos ?"

11 Estas palabras de Sarmiento me impresionan intensamente cada vez que las leo por su actualidad. Es indudable que hay una manera personal de despertar, como lo demuestra Peter Handke en Ein Jahr aus der Nacht gesprochen, anotando durante un año las palabras con que su narrador sale de la noche, que evoluciona además en el tiempo; pero es probable también que haya una manera argentina de despertar y preguntarse "quién soy", “dónde estoy", “¿cómo llegué hasta aquí ?". Cuando escribimos, el pasado es, en todo caso, ese desconcierto : el regusto con que la pesadilla dejada recientemente atrás 
perdura durante el tiempo del despertar. ¿Qué extensión, que profundidad, que oscuridad tiene ese sueño. ¿Vale, valió acaso la pena? Siempre está esa pregunta respecto a ese pasado que es el sueño, nuestro sueño, como bien diría Paul Valery en su Dialogue de l'arbre: "Mais, tes rêves, [...] Valent-ils au réveil d'avoir été rêvés? Es a partir del despertar, al ser escritos, que los sueños valen.

Cuando escribo, cuando escribimos, nunca esperamos escribir "literatura argentina". No esperamos escribir ni el Facundo, ni el Martín Fierro, ni La cautiva. Y no por falta de ambición. Comprendo, comprendemos, simplemente, que es imposible reconstruir no el significado que esos textos tuvieron en el siglo XIX, cuando fueron escritos y publicados un significado muy precario por cierto y sobre todo decepcionante si se estudia su recepción-, sino el que adquirieron a lo largo -o al menos en distintos momentos puntuales- del infatigable siglo XX. Algunos críticos argentinos han intentado estos últimos años representar el problema de la literatura argentina durante la última dictadura militar retomando la boutade de uno de los personajes de Respiración artificial de Ricardo Piglia. Un personaje de esta novela se pregunta : “QQuién de nosotros escribirá el Facundo?". La pregunta, más allá de toda broma, revela una suerte de síndrome propiamente argentino que yo llamaría de la "precursión". La palabra no existe pero debería ser inventada para un uso exclusivamente nuestro. Nadie puede hoy escribir el Facundo porque para escribir el Facundo es necesario haber nacido en la provincia de San Juan, cerca de la frontera con Chile, es necesario haber tenido que cruzar la cordillera de los Andes hacia el exilio, haber regresado, haber tenido que volver a partir; es necesario haber vivido en un país extranjero y escrito allí sobre el país natal ; es necesario haber encontrado a Echeverría en una Montevideo asediada, haber visitado un día de carnaval en Río de Janeiro en compañía del pintor Rugendas el jardín del Emperador, haber cruzado el Atlántico pensando en Fourier, haber encontrado en Francia a un extinto libertador latinoamericano; haber vuelto al país natal para participar de una campaña militar ; haber sido presidente de la República, haber hecho traer de los Estados Unidos la novedad de los rifles remingtons para diezmar entrerrianos; para escribir el Facundo es necesario haber perdido un hijo en una guerra contra el Paraguay; para escribir el Facundo, finalmente, es necesario, antes que nada, no haber querido escribir el Facundo.

13 Se me reprochará, indudablemente, el hecho de haber mezclado de manera indiscriminada, situaciones biográficas anteriores y posteriores al momento de la escritura del Facundo, haber confundido episodios del pasado y del futuro del autor. ¿Pero cuándo y cómo se escribe un libro como Facundo si no con la vida entera?

Quisiera intentar una aproximación a nuestro tema desde ese margen incansable que constituye la poesía. Porque la poesía, desde el pasado más profundo, en el corazón más incierto del siglo XIX, da cuenta, mejor que ningún otro lenguaje, de un cantar y un contar. Un contar-cantando que confunde para siempre los límites entre narración, ensayo y poema. Conviene no olvidar que el Martín Fierro puede ser leído como una novela, un ensayo sobre la vida nacional pero también, antes que nada, como un poema. No voy a entrar aquí en una discusión sobre el problema de los géneros en un texto como 
el Martín Fierro, pero se me ocurre proponer que la poesía plantea una dimensión del tiempo muy particular, que es la de la intimidad, que registra un estado esencial de la literatura argentina y donde la relación entre pasado y presente adquiere un carácter único.

Este territorio, tan pocas veces explorado, es el que Amaro Villanueva, poeta y ensayista complejo y secreto si lo hay, recorre como un visionario. Amaro Villanueva ejercitó, a un mismo tiempo, la crónica y el poema, el estudio cultural y el poético, el ensayo y el haikú. En su obra la poesía es justamente un terreno de prueba donde ejercitar las posibilidades del lenguaje. Me sirvo, para presentarlo, de un rápido panorama de su trayectoria poética realizado por D.G. Helder en la introducción al segundo volumen de la Obra completa :

Esa trayectoria parte hacia mediados de los años 20 bajo las pautas del postmodernismo (huellas de Lugones y Carriego, sencillismo de temática ciudadana de provincia), reconoce a finales de la década una inflexión historicista de tono seudoclásico (sonetos de exaltación regional), da un brusco giro en 1930 hacia la gauchesca política (más como una forma satírica de periodismo que de poesía propiamente dicha), profundiza la temática urbana (canto a las calles de Paraná, soneto a Carriego), se complementa con un capítulo de temática campesina (romances y romancillo de 1931), registra en 1935 un pico de materialismo histórico (la reescritura de un texto de Erenburg sobre la explotación del caucho, en realidad sobre la explotación humana), a continuación retorna al sencillismo costumbrista de ambiente provincial (sonetillos para la oreja), incursiona en una especie de criollismo tardovanguardista (haikus de temática y tono nativos), abre curso a un período de ejercitación barroca (sonetos dialectales de varios tipos), retoma la línea neogauchesca y nativista (el romance de don Escolástico, la tonada de Araya, las cuartetas del indio borracho, etc.), abre un capítulo de poesía partidaria (sonetos comunistas de los 50), reflota el sencillismo ahora con ambiente porteño (paseo sentimental en vísperas del otoño) y adopta finalmente en los 60 el lunfardo como lengua poética.

La poesía de Villanueva explora, entonces, todos los registros de la forma poética en busca de la expresión popular hasta llegar a las más extremas posibilidades de la neo-gauchesca, la neo-gauchi-política, el neo-lunfardo. Según observa Helder, con lucidez, la aparente heterogeneidad de la poesía de Villanueva desaparece cuando se la pone en paralelo con su obra de intelectual, con sus estudios de los lenguajes y formas populares, en particular en torno del mate, el Martín Fierro y el lunfardo. Y concluye Helder : "la contribución principal de Amaro Villanueva consiste en la indeclinable militancia intelectual con que opuso al esteticismo el postulado de una literatura al servicio de valores sociales que la trascienden".

Es indudable que sin Crítica y pico, El arte de cebar o El lenguaje del mate de Villanueva, un narrador-ensayista-poeta como Juan José Saer no hubiera podido escribir, en Nadie nada nunca, lo siguiente :

La pava de aluminio está apoyada sobre el reborde de la ventana, la mitad interna de la pared que el marco negro divide en dos. La levanto y lleno, despacio, el mate tibio que sostengo en la palma ahuecada de la otra mano. Cuando la infusión aguachenta en la que nadan dos o tres palitos exangües de yerba llega a ras del orificio, deposito la pava sobre el reborde de la ventana, me pongo la bombilla entre los labios y empiezo a chupar. El sabor, más insípido que amargo, del mate me llena la boca, y el líquido tibio, que me hace sudar, pasa por mi garganta, hasta que las últimas chupadas, que hacen subir por la bombilla a la boca cada vez menos líquido, terminan produciendo, en el fondo del mate, un murmullo ronco y apagado. 
la poesía de Villanueva, Edgardo Dobry, en otro estudio de la edición mencionada señala lo siguiente: "Dejó dicho, a su modo, que la propia voz es tan artificiosa como cualquiera de sus modulaciones transmutadas, que en Argentina son antiguas y huelen a nuevo o viceversa". La preocupación por una "lengua nacional", que viene desarrollando Dobry desde hace algunos años, tanto en sus estudios sobre El payador de Lugones como en sus ensayos sobre la poesía actual, se continúan en su propia obra. En el poema "La casita del hornero" de El lago de los botes, Dobry dialoga con ese paisaje extra-urbano, tan antiguo y tan nuevo a la luz de sus exploraciones, que es también el de la poesía de Helder:

La quinta de Funes era el gran solárium

de la Asociación Israelita de Beneficencia ;

mientras los viejos se hundían en narcótica

modorra a la sobremesa del asado

saltábamos el alambre estrellado del fondo

para entrar en la Argentina verdadera :

sulkis oxidados, olor a tambo,

pirámides los hormigueros,

arañas como sapos, perros

silvestres, ratas en los nidos de los pájaros

y víboras a la búsqueda de ratas.

Se marchaba

cantando entre explosiones de risas

si traíamos un nido de trofeo

esa oda boba de Lugones

aprendida en la primaria de memoria :

"La casita del hornero / tiene sala y tiene alcoba...".

Una "tierra baldía" que es común -si se piensa en El guadal de Helder- pero también propia o exclusiva de Dobry, que la sitúa en los fondos de una tradición judeo-argentina apenas explorada. Una tradición que mantiene en nuestra literatura una maravillosa marginalidad, que la literatura de Gerchunoff apenas ha distraído, y que se pone en evidencia en la vitalidad de la crónica testimonial de las colonias santafesinas y entrerrianas. Este poema de Dobry explora además, esa otra tradición, que tiene a Lugones como representante "bobo", pero que puede rastrearse en toda una inefable iconografía escolar : la "casa" del hornero como símbolo del abrigo nacional, tan sólida y tan frágil.

Cuadernos LIRICO, 10 | 2014 
Quería mencionar a estos dos poetas actuales, Helder y Dobry (con quienes por otra parte comparto algunos horizontes de trabajos y lecturas), para poner de relieve, en este caso a través de una lectura común de Villanueva, la preocupación por los problemas de la expresión que hunden también sus raíces en los orígenes de nuestro lenguaje literario argentino. Como Villanueva, Helder y Dobry hacen que lo antiguo huela a nuevo : como el lenguaje del gaucho, el lunfardo, o el voseo. En Argentina, en América en general, lo viejo es nuevo y lo nuevo es viejo de manera muy nuestra.

"Yo soy aquel que ayer nomás decía"... Este es el primer verso del primer poema de Cantos de vida y esperanza de Rubén Darío. Escrito y publicado en 1904, este poema fue incluido como pórtico a la primera edición del libro, de 1905. "Yo soy aquel que ayer nomás decía / el verso azul y la canción profana...". Aquellas "prosas" de ayer son hoy "canción". Gómez Carrillo consideraba el título de Prosas profanas como "algo belga" y se lo reprocha al autor puesto que debe esconder el libro para que "sus amigos de París no sonrían maliciosamente al hojearlo".

Más allá de las anécdotas, que de todos modos pertenecen al ámbito de la amistad, tan importante en poesía, el poeta abre el siglo planteando de manera admirable la relación, a un mismo tiempo íntima y pública, que mantiene con su propia historia poética. Intima porque sólo él puede medir esa distancia entre el "hoy" y el "ayer"; pública porque es consciente de haber creado un movimiento, el modernismo, cuya vigencia, espacial y temporalmente hablando, no depende de la vitalidad de su fundador. Con perplejidad muchos críticos establecen la muerte de Darío, en 1916, como el umbral que da paso al llamado "post-modernismo". Se abre un doble plano discursivo, íntimo y público, personal y colectivo, del decir y de la letra. Este verso, que revisita el pasado desde el presente, marca una tensión que perdurará durante todo el siglo.

La pacífica corrección, que va de la "prosa" al "canto", más allá de las bromas de la amistad y de los prejuicios de todo americano en el París de fin de siglo, tiene una resonancia local, que las palabras ponen en evidencia. Los poemas de Prosas profanas, propios del "ayer" del poeta, son también testimonio de su origen rioplatense (por más que "bufe el eunuco" extranjero) y el asencillamiento con que se continuará en las Misas herejes de Carriego es una prueba. Hay un doble ingreso marginal, desde la poesía y también desde el litoral argentino, a esta tradición post-modernista. Es en este contexto que deben leerse estos versos del siglo XX dedicados a un "sauce" :

Como una fiesta fluvial

de los bochornos de estío,

cuelga en la orilla del río

su fresca sombra el sauzal.

La clara luz de cristal

escribe en la onda una raya

y la linfa se desmaya

blandamente a la deriva,

como una deidad lasciva

que se desnuda en la playa.

Surge coqueta y prolija 
una ligera chalana

que distrae a la mañana

con su humilde baratija ;

se ríe y se regocija

el agua sobre la estela;

la fronda del sauce riela

y se deshila en caireles,

como ficticios pinceles

de una ilusoria acuarela.

Se trata de un fragmento del poema "El sauce" del poeta Daniel Elías, fechado en 1926, aunque publicado por primera vez de manera póstuma, en un diario de Concepción del Uruguay (Entre Ríos). En este poema de Elías, misteriosamente, como una suerte de criptograma que cambia de significado según el código de lectura, puede mirarse todo En el aura del sauce de Juan L. Ortiz. Podrá el sedimento del siglo XX, equívoco y confuso, posarse sobre su superficie, borrándolo de lo legible o recluyéndolo a archivos polvorientos. Y poco importa que una edición recién lo devuelva a la lectura a principios del XXI. Ya había estado leyéndose y comprendiéndose de manera secreta. "El sauce", por otra parte, fue publicado por primera vez en libro (también de manera póstuma) acompañando "Las alegrías del sol", magnífico y extenso poema dedicado a la luz entrerriana y no puedo no prolongar el mismo ejercicio en otro sentido : seguramente sin Las alegrías del sol sería improbable "Luz de provincia" de Carlos Mastronardi.

Tradiciones litorales del árbol y de la luz sin las cuales, ya todos lo habrán adivinado, sería difícil pensar la poesía y la prosa de Juan José Saer, Juan José Manauta o Arnaldo Calveyra. Y sin las cuales tampoco podría imaginarse la poesía argentina actual : pienso en poetas tan dispares, aunque deudores de una misma sangre, como Juan Manuel Inchauspe, Marilyn Contardi, Hugo Padeletti, Mirta Rosenberg, Miguel Ángel Federik, Martín Prieto, Daniel García Helder, Edgardo Dobry, Sonia Scarabelli o Francisco Bitar. Dice Federik, en el prólogo a la reciente edición de la Poesía completa de Elías : "Le bastaron memoria y mirada creyente para darle estatura a modestas cosas : el verdor de unas exiguas viñas con gorriones, la luz dominical de unos cielos apacibles, los estadios del día entre los sauces, la sombra andante de sus héroes anónimos, el trigo que nace después de las batallas y esos trabajos del sol que pone hombres de pie y sigue haciendo redondas las naranjas". Una enumeración que describe perfectamente la poesía de Elías pero también la de Federik, en la modulación de una luz sobre el río Uruguay prácticamente inédita en nuestras letras, al menos hasta que nos decidamos a incluir en ellas a la poesía de Circe Maia, Marosa di Giorgio y el mismo Federik.

Rápida y parcial conclusión : la escritura actual, sobre todo de ciertos textos potentes que dominan el "hoy" de la literatura argentina, reinventa sus tradiciones marginales y remonta sus raíces hacia el siglo XIX. El siglo XIX, aunque parezca paradójico, recién comienza a configurarse. Fue necesario, quizás, el cierre del siglo XX para adquirir la posibilidad de esta perspectiva. Esta tradición "marginal", o en todo caso "litoral", que nace con el post-modernismo y llega hasta Juan L. Ortiz o Juan José Saer, debe ser reconstruida. Aquí la crítica universitaria debe encontrar un campo de trabajo. Visto así el siglo XIX se vuelve cada vez más raro, más complejo y, curiosamente, más rico. 
No puedo dejar de señalar que la poesía de Daniel Elías y Amaro Villanueva apenas aparecen en el sistema de la poesía argentina. Estos autores no se encuentran por ejemplo en la magnífica y completa antología que editó en 2010 Jorge Monteleone (200 años de poesía argentina). Esto no es una crítica al trabajo de Monteleone, todo lo contrario porque uno de los méritos de toda buena antología es precisamente, en un panorama de la percepción actual, el de poner de relieve las ausencias.

Es comprensible el olvido, por otra parte, dada la escasa visibilidad de estos poetas en el patafísico sistema editorial argentino : las ediciones mencionadas de Villanueva y Elías son, respectivamente, de 2010 y 2013. Es así. Y este no es un dato accesorio. La historia de toda literatura, en particular la de una literatura "emergente" como es la argentina, está siempre escribiéndose en sus márgenes, en sus fallas, sus ausencias o, en todo caso, en esas presencias fantasmáticas tan familiares (todo fantasma es familiar). A la crítica y en particular a la crítica universitaria le cabe este trabajo de restitución. Me dirijo en particular a los estudiantes de literatura que se encuentran en este auditorio. Lo primero que debe comprender quien se inicia en el estudio de una literatura como la argentina es que lo más interesante se encuentra siempre cruzando la frontera.

Los que escribimos, por nuestra parte, debemos lograr ese lugar, entre el yo y el nosotros, donde el otro encuentre su abrigo. Retomo así, para concluir, la cita de Said mencionada al comienzo de este trabajo a modo de epígrafe. Pertenece a un último prefacio escrito por el autor en 2003, poco tiempo antes morir, en ocasión de una nueva edición su libro sobre el Orientalismo. Es curioso, para volver también al comienzo de esta ponencia, descubrir de qué manera, con aquellos "cautivos" o "cautivas", nuestra literatura buscaba incluirse en una determinada tradición occidental. Una tradición compleja, por otra parte, porque el tema del cautivo se encuentra precisamente en la encrucijada entre occidente y oriente o al menos con un determinado imaginario que occidente construye respecto a su oriente. De cautivos y cautivas está poblada nuestra cultura occidentaloriental y al incluirlos en sus obras nuestros escritores o pintores del XIX o del XX perseguían un objetivo doble : reconocer lo propio reflejado en un tema universal. Los cautivos somos nosotros y los otros: estepas y desiertos confunden allí, todavía, sus horizontes, magistralmente.

Paradoja incesante : nos reconocemos en el lugar mismo en que comenzamos a perdernos.

Octubre 2013

\section{NOTAS}

1. La frase de Joyce, del segundo capítulo del Ulises, en boca de Stephen Dedalus ("History is a nightmare from which I am trying to awake"), me llega en realidad de Saer, que la retomó en un controvertido coloquio realizado en Santa Fe, hacia 1997 o 1998, a propósito justamente de la relación entre la ficción y la historia. 